\title{
ASPECTOS CURRÍCULARES DA FORMAÇÃO UNIVERSITÁRIA EM EDUCAÇÃO FÍSICA PARA ATUAÇÃO NA EDUCAÇÃO INCLUSIVA
}

\author{
Paulo José Barbosa Gutierres Filho \\ Universidade do Estado de Santa Catarina, Florianopólis, Santa Catarina, Brasil \\ Maria Dolores Alves Ferreira Monteiro \\ Universidade de Trás os Montes e Alto Douro, Vila Real, Portugal \\ Rudney da Silva \\ Universidade do Estado de Santa Catarina, Florianopólis, Santa Catarina, Brasil \\ Carla Regiane Vargas \\ Escola de Educação Básica São João Batista, Brusque, Santa Catarina, Brasil
}

\begin{abstract}
Resumo
Este estudo buscou analisar os aspectos curriculares relacionados à educação inclusiva tratados nas disciplinas de atividade motora adaptada ou suas correlatas na formação em Educação Física do Estado de Santa Catarina.. Os sujeitos foram selecionados aleatoriamente $(n=17)$ em 12 Instituições de Ensino Superior catarinenses. Os dados foram coletados por meio de entrevista semi-estruturada e questionário. Os dados categoriais foram analisados por meio de análise de conteúdo e os dados numéricos por meio de estatística descritiva. Pode-se concluir que os participantes percebem que os aspectos curriculares têm buscado a formação para atuação inclusiva, porém, através de ações docentes isoladas e com carências de recursos físicos, humanos e metodológicos, gerando assim, fragilidades que afetam a formação universitária para atuação inclusiva. Pode-se, também, concluir que os participantes entendem que as disciplinas na área da adaptada apresentam prevalentemente caráter teórico-prático e técnico-terapêutico e que a docência é realizada por professores relativamente novos na docência universitária, qualificados em nível stricto sensu e que não possuem alunos com deficiência.
\end{abstract}

Palavras-Chaves: Docentes. Educação Física e Treinamento. Educação Superior.

Pensar a Prática, Goiânia, v. 17, n. 1, p. 01-294, jan./mar. 2014 


\section{Introdução}

No universo e na complexidade relacionada às dificuldades inerentes a educação inclusiva, a precária formação de professores de ensino superior em Educação Física é evidente (RODRIGUES, 2003, 2004; GOLDER, NORWICH E BAYLISS, 2005; SKARBREVIK, 2005; AMMAH e HODGE, 2006; SATO, HODGE, MURATA e MAEDA, 2007; MONTEIRO 2008; GORGATTI e DE ROSE Jr., 2009), pois a formação docente no Brasil ainda se configura como um dos principais óbices à educação inclusiva (GORGATTI, PENTEADO, PINGE e DE ROSE JÚNIOR, 2004; PALLA e CASTRO, 2004; AGUIAR e DUARTE, 2005; FALKENBACH ET AL., 2007a; FALKENBACH ET AL., 2007b; BARBOSA, CESÁRIO E BENTO, 2009; GORGATTI e DE ROSE JR., 2009; SILVA e SILVEIRA JUNIOR, 2009; SILVA e REIS, 2011). No caso da formação de professores no ensino superior em Educação Física no Brasil, pode-se apontar a prevalência das áreas técnicas em detrimento às áreas pedagógicas (SILVA, 1993; FALKENBACH ET AL., 2007a, FALKENBACH et al., 2007b; FALKENBACH, 2010), destacando deste modo as fragilidades que podem afetar o processo de educação inclusiva nos diferentes níveis de ensino, inclusive na universidade (RODRIGUES, 2006; FALKENBACH, 2010).

As dificuldades inerentes aos processos de educação inclusiva levam educadores de todos os níveis de ensino, inclusive de ensino superior, a se confrontarem com mudanças de perspectiva e de intervenção profissional (PEREIRA, 1999; RODRIGUES, 2003, 2006; FALKENBACH, 2010) provocadas por determinantes legais, socioeconômicos e pedagógicos, tais como o distanciamento entre a legislação e sua aplicação prática, as opções curriculares e realidade social e econômica e ainda, as condições institucionais e exigências relacionados às pessoas com deficiência (PCD). Neste sentido, torna-se necessário não só a proposição de políticas públicas educacionais voltadas para práticas mais inclusivas, mas também, a adequação da formação de professores visando o desenvolvimento de habilidades e competências necessárias à realidade educacional brasileira (NUNES SOBRINHO; NAUJORKS, 2001). Contudo, deve-se considerar que estas problemáticas não são exclusivas da realidade brasileira, pois a formação de professores de Educação Física para atuação na educação inclusiva tem sido tratada de forma insuficiente em diversos países (RODRIGUES, 2006; SATO, HODGE, MURATA e MAEDA, 2007; BRASIL, 2008; MONTEIRO, 2008; GORGATTI e DE ROSE Jr., 2009).

No âmbito da Educação Física portuguesa, Rodrigues (2003) aponta que os conteúdos de informação sobre as PCD são freqüentemente inexistentes ou pouco direcionados para a resolução de problemas concretos de planejamento, intervenção e avaliação necessária à atuação na educação inclusiva. No contexto da Educação Física brasileira, Tolocka (2008) refere que nas últimas décadas às PCD permaneceram excluídas por não atenderem determinadas exigências desta área, 
ignorando a diversidade humana do contexto educacional por meio de práticas seletivas e segregadoras, pois, apesar de ser promissora disciplina à inclusão escolar (PEDRINELLI, 2002; RODRIGUES，2006; FALKENBACH，2010), ainda pode-se constatar que o currículo na formação de professores em Educação Física ainda carece de conteúdos sobre inclusão, distanciando-se das discussões acadêmicas sobre este fenômeno (RIZZO e KIRKENDALL, 1995, RODRIGUES, 2006).

Duarte (2003) relata que somente a partir da última década, os cursos de Educação Física colocaram em seus programas curriculares conteúdos relativos às PCD e que o material didático que trata das formas de trabalho com essa população, escrito em língua portuguesa ainda é escasso. Portanto, torna-se necessário que a universidade reflita sobre suas dificuldades pedagógicas, pois os estudos permitem destacar a frágil formação inicial, uma vez que a ação pedagógica é desempenhada menos de forma acadêmica e mais nos conceitos do senso comum e da vivência dos respectivos professores (RODRIGUES, 2004; AGUIAR e DUARTE, 2005; CRUZ E FERREIRA, 2005; FALKENBACH, 2010).

Desde modo, considerando as problemáticas legais, curriculares, estruturais e humanas relacionadas à realidade universitária de formação profissional para atuação com PCD, principalmente aquelas em contínua transformação pelos determinantes políticos econômicos e sociais, este estudo tem como objetivo principal analisar os aspectos curriculares associados à formação no ensino superior em analisar os aspectos curriculares relacionados à educação inclusiva desenvolvidos nas disciplinas de atividade motora adaptada ou suas correlatas na formação em Educação Física do Estado de Santa Catarina.

\section{Método}

Este artigo foi caracterizado como documental, descritivo e de campo, realizado através de procedimentos qualitativos e quantitativos de coleta e análise das informações (BOGDAN; BIKLEN, 1994; LAVILLE e DIONNE, 1999; ALVESMAZZOTI e GEWANDSZNAJDER, 2002). O estudo foi aprovado pelo Comitê de Ética em Pesquisa envolvendo Seres Humanos, da Universidade do Estado de Santa Catarina (Protocolo 56/2010).

\section{Sujeitos}

Os sujeitos foram identificados conforme os seguintes critérios de seleção definidos previamente: a) pertencer à Instituição de ensino superior devidamente credenciada no Ministério da Educação; b) pertencer à Instituição do Estado de Santa Catarina que permitisse livre acesso às informações; c) atuar na disciplina de atividade motora adaptada ou suas correlatas, de cursos de ensino superior em 
Educação Física; d) ter estabilidade profissional na instituição; e) apresentar intenção de participar do estudo de forma livre e consentida.

Os levantamentos preliminares permitiram identificar 32 IES, porém, sete não atendiam integralmente aos critérios de seleção. Foram selecionadas 12 IES elegíveis através de acessibilidade por estratos (por região): 1 - Litoral; 2 - Nordeste; 3 - Vale do Itajaí: 4 - Planalto Norte: 5 - Planalto Serrano: 6 - Sul: 7 Oeste, com sorteio aleatorio de três sujeitos para a realização do estudo piloto e mais 14 professores para a coleta de dados, que atendiam aos critérios de seleção. Deste modo, foi investigado um total de 17 sujeitos (n) em duas IES públicas e dez IES privadas, oriundas das sete meso-regiões do Estado de Santa Catarina.

\section{Quadro operacional}

A adoção de um quadro operacional com os indicadores deste estudo possibilitou a superação da linguagem abstrata dos dados teóricos para a linguagem concreta dos dados levantados (LAVILLE e DIONNE, 1999; SILVA, 2006). Os indicadores foram agrupados em categorias, subcategorias e temas conforme Figura 1.

\begin{tabular}{|c|c|c|c|}
\hline CATEGORIA & SUBCATEGORIAS & TEMAS & SUBTEMAS \\
\hline \multirow{5}{*}{$\begin{array}{l}\text { Formação universitá- } \\
\text { ria em Educação Físi- } \\
\text { ca para atuação na } \\
\text { educação inclusiva }\end{array}$} & \multirow{3}{*}{$\begin{array}{l}\text { Ensino Superior em Edu- } \\
\text { cação Física }\end{array}$} & $\begin{array}{l}\text { Currículo universitá- } \\
\text { rio }\end{array}$ & $\begin{array}{l}\text { Obrigatoriedade; } \\
\text { Especificidade }\end{array}$ \\
\hline & & $\begin{array}{l}\text { Condições } \\
\text { Institucionais }\end{array}$ & $\begin{array}{l}\text { Condições físicas; } \\
\text { Acessibilidade }\end{array}$ \\
\hline & & $\begin{array}{l}\text { Formação profissio- } \\
\text { nal }\end{array}$ & $\begin{array}{l}\text { Interações profissio- } \\
\text { nais; } \\
\text { Formação tecnocien- } \\
\text { tífico }\end{array}$ \\
\hline & \multirow{2}{*}{$\begin{array}{l}\text { Ensino superior relacio- } \\
\text { nado à inclusão }\end{array}$} & Mudanças sociais & $\begin{array}{l}\text { Interações sociais; } \\
\text { Relações interpesso- } \\
\text { ais }\end{array}$ \\
\hline & & $\begin{array}{r}\text { Relação } \\
\text { disciplinar }\end{array}$ & $\begin{array}{l}\text { Disciplinas regulares; } \\
\text { Disciplinas adaptadas }\end{array}$ \\
\hline
\end{tabular}

Figura 1: Quadro operacional da pesquisa.

\section{Instrumentos}

Os dados verbais foram coletados através de entrevista semi-estruturada e de questionário misto, construídos especificamente para este estudo e validados através de estudo piloto (NEGRINE, 1999; LAVILLE e DIONNE, 1999; ALVESMAZZOTI e GEWANDSZNAJDER, 2002). A entrevista semi-estruturada foi composta de roteiro de seis questões abertas elaboradas previamente, com base nas seguintes temáticas: a) mudanças sociais na formação universitária; b) bases 
científicas da formação universitária; c) mudanças no contexto científico; d) recursos humanos; e) recursos didáticos; f) recursos materiais; g) obrigatoriedade curricular da área de adaptada; h) condições docentes; i) condições discentes; j) exigências legais; 1) demandas profissionais.

$\mathrm{O}$ questionário foi composto de questões abertas e fechadas sobre as seguintes temáticas: a) gênero; b) data de nascimento; c) formação acadêmica; d) qualificação acadêmica; e) tempo de experiência no ensino superior em Educação Física; f) tempo de experiência no ensino superior na área de adaptada; g) tipo de universidade; h) docência para alunos com deficiência no ensino superior (quantidade de alunos, tipo de deficiência, grau de deficiência, experiência em outros níveis); i) participação em cursos na área de adaptada; j) auto/percepção sobre o ensino de alunos com deficiência.

\section{Procedimentos}

O sorteio dos sujeitos foi realizado aleatoriamente através de codificação despersonalizada previamente atribuída ao total de professores existentes nas Instituições identificadas no levantamento preliminar. Os procedimentos do estudo piloto de avaliação da fidedignidade e validade das questões dos instrumentos foram realizados pelos próprios sujeitos através de análise qualitativa, conforme agendamento proposto pelos mesmos. Este procedimento foi possível, pois além de respondentes, os sujeitos também são, pela sua própria atuação, especialistas na área de atividade motora adaptada.

Os dados foram coletados após o recolhimento do termo de consentimento livre e esclarecido devidamente assinado. As entrevistas foram realizadas em local, data e horário previamente agendado pelos participantes. Os questionários foram coletados concomitantemente às entrevistas ou separadamente conforme escolha dos sujeitos. O processo de seleção apontou que 06 sujeitos não se dispuseram a participar do estudo. Já após a seleção, nenhum dos sujeitos se negou a responder a qualquer questão, integralizando o roteiro da entrevista inicial e o preenchimento dos questionários. As devolutivas dos dados foram realizadas apenas aos sujeitos que a solicitaram.

A sistematização e apresentação das informações foram realizadas através de três eixos norteadores: a) dados do levantamento preliminar; b) dados ocupacionais e sócio-demográficos; e c) informações sobre o ensino universitário relacionado à inclusão. As análises e interpretações das informações foram desenvolvidas através da análise categorial proveniente da análise de conteúdo, que após a codificação e sistematização, procedeu a categorização dos conteúdos em blocos temáticos. As categorias principais foram obtidas através da identificação e seleção das unidades de significância. (LAVILLE e DIONNE, 1999; BARDIN, 2000; ALVES-MAZZOTI e GEWANDSZNAJDER, 2002). Os dados numéricos 
foram analisados por meio da estatística descritiva, adotando as medidas de freqüência e de tendência central (mínima, máxima, média, desvio padrão).

\section{Resultados e discussão}

Dados institucionais preliminares

Os levantamentos realizados nos sítios eletrônicos das Instituições de Ensino Superior do Estado de Santa Catarina que oferecem o curso de Educação Física no ano de 2010 permitiram constatar que existe uma distribuição não linear nas sete regiões de Santa Catarina (Tabela 1) e que prevalecem os cursos de licenciatura $(58 \%)$ em detrimento ao de bacharelado (42\%).

Tabela 1: Relação das instituições de ensino superior por regiões no Estado de Santa Catarina, no ano de 2010.

\begin{tabular}{lll}
\hline & IES & \\
\cline { 2 - 3 } Região & $(\mathbf{n})$ & $(\mathbf{\% )}$ \\
\hline Litoral & 9 & 28 \\
Oeste & 6 & 19 \\
Vale do Itajaí & 5 & 16 \\
Meio Oeste & 4 & 13 \\
Nordeste & 3 & 9 \\
Planalto Norte & 3 & 9 \\
Planalto Serrano & 2 & 6 \\
\hline Total & 32 & 100 \\
\hline
\end{tabular}

Estes resultados demonstram, ainda, discrepâncias entre a existência real de cursos de ensino superior em Educação Física, pois os levantamentos preliminares identificaram a existência de 32 instituições, e os dados disponibilizados pelo Ministério da Educação no ano de 2009, apontou a regularidade de 25 instituições. Contudo, deve-se apontar que estas discrepâncias podem ocorrer pelas próprias características administrativas e legais do ensino superior no Brasil, haja vista ser possível ocorrer à abertura de novos cursos universitários, desde que atendam aos requisitos exigidos, de forma concomitante a sua tramitação nos órgãos estaduais e federais.

Dados ocupacionais e sociodemográficos

As análises frequenciais dos dados numéricos demonstraram que a maioria é do sexo masculino $(\mathrm{n}=9)$, formada tanto na licenciatura quanto no bacharelado $(\mathrm{n}=9)$, qualificada em nível de mestrado $(\mathrm{f}=10)$, principalmente na área de Educação Física $(\mathrm{f}=7)$, oriunda de instituições privadas $(\mathrm{n}=7)$ e ministrante de dis- 
ciplinas teórico/práticas ( $\mathrm{f}=14)$. A análise descritiva dos dados apontou valores de medida média de 42,2 anos de idade, 17,4 anos de graduação, 8,67 anos de mestrado, 3,5 anos de docência universitária e 2,9 anos de docência universitária em disciplinas na área de adaptada.

$\mathrm{O}$ levantamento das disciplinas ministradas pelos participantes apontou as seguintes disciplinas: Teoria e Metodologia dos Esportes Adaptados (P1); Orientação de Estágio em Educação Física Adaptada (P2; P3, P16); Reeducação Física (P3) Atividade Física Adaptada (P3); Esportes Adaptados (P4, P5); Atividade Motora Adaptada (P5, P9); Processo de Inclusão (P6); Atividades Físico-Esportivas para Portadores de Necessidades Especiais (P7); Educação Física Especial (P8, P10); Educação Física para Pessoas com Necessidades Especiais (P11); Educação Física Adaptada (P12, P14, P17); Fundamentos e Metodologia da Educação Física Especial (P13); Fundamentos da Educação Física para Pessoas Portadoras de Necessidades Especiais (P15); Fundamentos da Educação Física Adaptada (P16), Estágio em Educação Física Adaptada (P16).

Informações sobre o ensino superior em Educação Física relacionado à inclusão

A partir das análises de conteúdo sobre os resultados verbais dos participantes, pode-se verificar que os participantes acreditam que a formação no ensino superior em Educação Física do Estado de Santa Catarina para atuação na educação inclusiva, encontra-se ainda de forma incipiente, com algumas ações isoladas de professores que trazem vida prática a esta necessidade cada vez mais emergente, e que esta crença é coerente com resultados encontrados por diversos estudos (FILUS e MARTINS JR., 2004; MAUERBERG DE CASTRO, 2005; GORGATTI, DA COSTA, 2008). Identificou-se ainda, que estas questões relacionamse majoritariamente às carências de recursos físicos, humanos e metodológicos na formação em Educação Física para atuação na educação inclusiva, gerando fragilidades que afetam todo o processo de inclusão universidade.

No que se refere aos aspectos curriculares do ensino superior em Educação Física para atuação na educação inclusiva, constatou-se que os participantes entendem que por um lado houve grandes avanços a partir da reestruturação curricular dos cursos de formação inicial, devido à obrigatoriedade de disciplinas que abordam temáticas voltadas para PCD nos currículos dos cursos de Licenciatura e Bacharelado, mas por outro, devido à obrigatoriedade e à força da Lei, está se enfrentando inúmeros óbices, principalmente pela dificuldade de lidar com a diferença existente no contexto educacional.

A disciplina de Educação Física, considerada componente curricular obrigatório da educação básica (BRASIL, 1996), pode oferecer às novas gerações um papel social de relevância no campo educacional. Entretanto, deve-se atentar que esta consideração exige do professor de Educação Física um repensar de suas intervenções profissionais e, consequentemente, do currículo devidamente estrutu- 
rado para atender a diversidade humana que se apresenta, pois exercer a sua obrigatoriedade somente pela força da Lei pode provocar consequências negativas a esta área (OLIVEIRA, 2001).

Este entendimento sobre a imposição legal da Educação Física pode ser exemplificada pelo fragmento do discurso do Participante 15 ao analisar que a obrigatoriedade "[...] é mal necessário. Tem que ser obrigatório porque se não colocar como obrigatório as pessoas não fazem. Agora [...] o conteúdo relacionado às PCD poderia também estar perfeitamente disperso nas outras disciplinas [...] mas a principal desculpa dos profissionais continua sendo a idéia de que precisa ser um profissional altamente especializado para trabalhar com PCD [...]". O Participante 16 reforça o entendimento destas questões quando afirma dizendo "[...] primeiro que a obrigatoriedade é o passo rumo à liberdade. Não tem jeito, todo fenômeno antes de ser liberto, ele passou pela obrigatoriedade legal da questão. Não tem como fugir. Então a obrigatoriedade curricular que o conselho federal de educação impõe a todos os cursos de licenciatura é uma necessidade. Por que é uma necessidade? Porque é preciso pensar que existem diferentes níveis de maturidade social em diferentes grupos sociais, em diferentes momentos históricos [...]".

Filus e Martins Jr. (2004) apontam que a formação profissional oferecida pelos cursos de Educação Física é um tanto ineficaz, pois seus estudos apontam insatisfações com a ausência de disciplinas de Educação Física Adaptada em suas formações, demonstrando que os cursos de EF ainda carecem de conteúdos relacionados às $\mathrm{PCD}$, inclusive compartilhados com as demais disciplinas do currículo desta área.

Esta idealidade de uma integração curricular, entretanto, não é realidade no Estado de Santa Catarina, pois, conforme a fala do Participante 2, pode-se apontar que atualmente "[...] os alunos passam sete fases sem saber nada, praticamente $o$ currículo da Educação Física inteiro, e quando ele chega na oitava fase tem uma enxurrada de disciplinas só sobre deficiência [...]", o que é reforçado pelo Participante 3 quando ele afirma que [...] teoricamente o aluno não tem esse conhecimento sobre as PCD [...] não existe uma formação, uma experiência cientifica sobre o ensino relacionado às $P C D[\ldots]$ ".

Mauerberg de Castro (2005) retrata esta realidade de organizar um programa de atividade física adaptada em um currículo de Educação Física, apontando que os componentes e conjuntos de áreas de conhecimento que atendem a atividade física adaptada nem sempre estão claros devido a divisão de conteúdos desta disciplina ser centrada nas incapacidades e nas deficiências. Gorgatti e da Costa (2008) demonstram que é fundamental a reflexão sobre como as competências acadêmicas e profissionais podem ser desenvolvidas em uma só disciplina, em um só curso de formação generalista, pois a visão contemporânea de formação em Educação Física Adaptada enfatiza muito mais as adaptações e habilidades de ensino do que a elaboração de programas específicos. Reid (2000) defende ainda, a 
idéia de difusão de conhecimentos ao longo do curso, onde vários temas poderiam e deveriam ser incluídos em outras disciplinas da graduação.

O discurso dos Participantes 15 e 17 reforça o entendimento destas questões quando referem que "[...] o curso era de três anos, somente depois de 1987 que o currículo da Educação Física foi mudado, onde saiu à primeira proposta de alteração curricular. As primeiras turmas ocorreram por volta de 1992, 1993 com esse currículo de quatro anos e a disciplina de adaptada como obrigatória [...] no meu tempo eu não tive essa disciplina [...] nós não tínhamos formação na realidade para trabalhar [...] eu comecei com essa disciplina como obrigatória no currículo em 1994. A disciplina não tinha uma estrutura para ser desenvolvida [...] e dai, por conseguinte, nós tínhamos uma idéia equivocada das PCD [...]”.

Pode-se apontar que, no Brasil, as experiências de exclusão são vinculadas às práticas pedagógicas excludentes de professores do ensino superior em Educação Física, pois prevalecem as áreas técnicas em detrimento às áreas pedagógicas. Ghiraldelli Jr. (2001) ilustra esta questão quando refere que a disciplina de Educação Física é reconhecida por se embasar, historicamente, nas abordagens tradicionais e comportamentalista, competitivista e tecnicista, que reproduz nas aulas, o esporte, ou seja, como ele se apresenta na sua originalidade e os demais conteúdos ficam submetidos a visões que são reflexos do desporto de rendimento.

As influências competitivistas e tecnicistas podem ser verificadas no fragmento do discurso do Participante 15 que afirma "[...] a Educação Física, seguramente, é a disciplina que mais discrimina as pessoas sobre todos os aspectos, porque tudo o que o professor quer é um aluno que seja extremamente apto para fazer as atividades que ele está propondo [...] lidar com a diferença para o professor de Educação Física em geral é algo que é pouco trabalhado nas várias disciplinas da formação do profissional [...]".

Para Falkenbach (2010) a Educação Física caracteriza-se pela sua história como uma prática seletiva, segregadora e técnica, podendo ser compreendida como a área pedagógica da escola com menor tendência para as finalidades da inclusão que, de certa forma, justifica-se pelo fato dos projetos pedagógicos dos cursos de formação de professores de Educação Física apresentar pouco conteúdo quando o tema é inclusão. Deste modo, torna-se relevante que essa discussão se inicie no cerne da formação universitária em Educação Física, porque, mais do que iniciar esse debate, é preciso que as instituições ofereçam subsídios para que ele se fortaleça e não se encerre na formação inicial, pois o processo de inclusão/exclusão é dialético e multifacetado, além de contribuir para o desenvolvimento pleno de todas as potencialidades do aluno, que, de acordo com os Parâmetros Curriculares Nacionais, acaba sendo um dos objetivos da disciplina de Educação Física (BRASIL, 2000).

Um dos marcos da transformação universitária em Educação Física no Brasil foi à publicação da Resolução 03/1987/CFE, que determinou a reestruturação dos cursos de graduação nesta área, propondo, inclusive, a inserção da área de 
adaptada nos currículos de Educação Física (BRASIL, 1987). A Resolução 03/1987/CFE propunha ainda um período mínimo de duração, bem como a caracterização de disciplinas e de conteúdos específicos das diversas áreas da Educação Física (BRASIL, 1987). Deste modo, pode-se considerar que as mudanças exigidas na época representaram uma verdadeira emancipação da Educação Física no Brasil, inclusive para as áreas relacionadas à área de adaptada (BARROS, 1995), e o estabelecimento de novas disciplinas para a composição de um novo modelo de currículo permitiu a formação de um professor de Educação Física supostamente apto para trabalhar com PCD, pois a Resolução 03/1987/CFE possibilitou ainda uma formação inicial em Educação Física voltada à sistematização de conhecimentos a serem desenvolvidos com mais clareza frente à formação geral humanística e técnica e o aprofundamento de conhecimentos relacionados (BRASIL, 1987; ILHA, 2010).

Neste contexto, os cursos foram obrigados a oferecer em suas grades curriculares pelo menos uma disciplina que abordasse a questão das PCD, porém, estas poderiam ser obrigatórias ou optativas (GOMES, 2007). Atualmente o currículo é considerado como um conjunto articulado e normatizado de saberes dirigidos por uma determinada ordem estabelecida, em um campo em que materializam as representações, os conteúdos e significados culturais, pressupõe o atendimento às diversas demandas sociais e profissionais, independentemente das suas especificidades ou obrigatoriedade (MOREIRA e SILVA, 1995; MAUERBERG DE CASTRO, 2005; PEDRINELLI e VERENGUER, 2005).

No que se refere às condições institucionais da formação universitária em Educação Física para atuação na educação inclusiva, constatou-se que os participantes percebem que as realidades são majoritariamente precárias no que tange às condições físicas, principalmente em termos de acessibilidade física, além de condições institucionais docentes e discentes que provocam o distanciamento entre o aluno com e sem deficiência e entre o professor de Educação Física regular e o professor da área de Educação Física adaptada.

Este distanciamento docente e discente, pode ser observado no fragmento do discurso do Participante 1, quando aponta que "[...] as diferentes abordagens e metodologias de você instrumentalizar os alunos para trabalhar com PCD, ainda são muito restritas às nossas disciplinas [...] são raros os professores de outras áreas, eu to sendo até muito bom, em raros [...] que buscam, na sua matéria especifica, dar essas informações [...]".

Para Silva Filho e Silva (2008) a formação docente ainda apresenta necessidades ao ensino inclusivo com a "inclusão excludente", em que mesmo estando na instituição as PCD ficam excluídas. Como reflexo, existe cada vez maior o número de PCD em todos os níveis de ensino, da educação infantil ao ensino superior, pois não se questiona se a escola deve ou não aceitar a matrícula de todos os alunos, mas, sim, a intencionalidade e a qualidade do que tem sido proposto. Isto ocorre porque a inclusão é um direito constitucional (BRASIL, 1988). Como 
conseqüências deste direito fundamental, nenhuma discriminação de espécie alguma pode impedir o acesso à educação superior (BRASIL, 1988). Este é um compromisso internacional que remonta à década de 1940, mas que somente nos últimos anos tem revelado sua consciência vigorosa (SANTOS, 2010).

A inclusão é um movimento mundial pautado na Declaração Universal dos Direitos Humanos que supera ações locais e regionais, pois exige discussões globais que considerem as singularidades e diferenças culturais existentes no mundo. No Brasil a inclusão está fundamentada em inúmeros documentos, tais como, LDBEN 9.394/1996, resolução CNE/CP 1/2002, lei 11.096/2005, decreto 5.773/2006 e Plano de Desenvolvimento da Educação de 2007 (BRASIL, 1996; BRASIL, 2002; BRASIL, 2005; BRASIL, 2006; BRASIL, 2007). Deve-se destacar que para a LDBEN 9.394/1996 o ensino será ministrado com base nos princípios de igualdade de condições para o acesso e permanência na escola, de liberdade de aprender, ensinar, pesquisar e divulgar a cultura, o pensamento, a arte e o saber, do pluralismo de idéias e de concepções pedagógicas e do respeito à liberdade e apreço à tolerância (BRASIL, 1996). Entretanto, se por um lado tais princípios expressam a dimensão de culturas inclusivas, porque divulgam e fomentam valores inclusivos capazes de construir uma comunidade acadêmica com características democráticas que contemple as diferenças, por outro, há ainda, muitos aspectos humanos, físicos e metodológicos que emperram os avanços na educação inclusiva.

Entretanto, todas estas garantias e metas não condizem com a realidade da formação em Educação Física para atuação na educação inclusiva, pois isto se observa na fala do Participante 15 quando ele refere que "[...] o recurso humano que tem na universidade para atender toda esta demanda sou eu [...] falar de recursos humanos é falar de mim [...] o problema é exatamente esse, entende? hoje em dia, você tem materiais didáticos, o problema está nos recursos humanos, nos profissionais e na estrutura da universidade que é fragmentada dentro do contexto de formação [...]".

Deste modo, as carências de recursos físicos, humanos e metodológicos na formação em Educação Física do Estado de Santa Catarina para atuação na educação inclusiva, geram fragilidades que afetam todo o processo de educação inclusiva na universidade, pois, apesar deste Estado ser uma das unidades nacionais de destaque econômico e social na realidade Brasileira, pode-se perceber que a inclusão educacional ainda atinge uma parcela muito pequena da população universitária (SILVA FILHO e SILVA, 2008).

No que se refere às mudanças sociais ocorridas no ensino superior em Educação Física para atuação na educação inclusiva, verificou-se que os participantes apontam que ocorre uma desinformação generalizada, devido principalmente à velocidade das informações, mas também devido ao desinteresse na busca pessoal e profissional por essas informações.

Este afastamento entre o conhecimento e a realidade é apontado pelo Participante 15, quando assinala que "[...] dentro das universidades há muitos profes- 
sores mal formados, muitos professores desinformados, que acabam ou lidando com a sua atividade profissional como "bico" ou como santuário onde ele que determina o que é e o que não é [...] logo, precisa-se urgentemente de um professor de ensino superior que esteja amplamente conectado com as coisas que estão acontecendo. E não é o que acontece hoje [...] basta olhar para o corpo de professores no ensino superior em Educação Física, quais desses professores efetivamente se atualizaram ao longo do tempo? Quais estão acessando as redes sociais para ver o que está acontecendo, para ver como é que as PCD estão se virando hoje? [...] enfim, definitivamente a universidade não consegue acompanhar as mudanças sociais [...]".

Deste modo, a Educação Física, enquanto área de conhecimento, ainda possui fragilidades que podem afetar o processo de educação inclusiva nos diferentes níveis de ensino, inclusive na universidade, pois a formação de professores no Brasil ainda se configura como um dos principais desafios à educação inclusiva, até porque ainda existem déficits na formação para atuação na educação inclusiva e que esta tem sido tratada de forma insuficiente em diversos países, principalmente pela ausência de conhecimentos concretos de planejamento, intervenção e avaliação necessários à atuação junto à diversidade humana inerente à educação inclusiva (PEDRINELLI, 2002; RODRIGUES, 2003; 2006; TOLOCKA, 2008; SILVA e SILVEIRA JUNIOR, 2009; FALKENBACH, 2010). Diante destas discussões, pode-se constatar que a formação de professores em Educação Física ainda carece de conteúdos sobre inclusão, distanciando-se das discussões acadêmicas sobre este fenômeno. Porém, torna-se necessário que a universidade reflita sobre suas dificuldades pedagógicas, recursos físicos, humanos e metodológicos, e ainda atente para mudanças sociais e epistemológicas, pois os estudos permitem destacar a frágil formação inicial baseada em ações pedagógicas cada vez menos acadêmicas e cada vez mais baseadas em conceitos pessoais e de senso comum (RODRIGUES, 2004; FALKENBACH, 2010).

\section{Conclusões}

A partir do reconhecimento das características dos sujeitos e das instituições investigadas, pode-se concluir que existem discrepâncias entre a realidade do ensino superior em Educação Física e os dados governamentais oficiais que legalizam as instituições universitárias no Brasil. Pode-se, também, concluir que as disciplinas na área da adaptada apresentam prevalentemente caráter teóricoprático e técnico-terapêutico e que a docência é realizada por professores relativamente novos na docência universitária, qualificados em nível stricto sensu e que não possuem alunos com deficiência. Já o posicionamento cuidadoso aplicado a esta pesquisa, tanto inerentes aos pesquisados quanto ao pesquisador, permitem concluir ainda, que os participantes acreditam que os aspectos curriculares têm buscado a formação para atuação inclusiva, porém, através de ações docentes 
isoladas e com carências de recursos físicos, humanos e metodológicos, gerando assim, fragilidades que afetam a formação universitária para atuação inclusiva.

\title{
CURRICULAR ASPECTS OF UNIVERSITY TRAINING IN PHYSICAL EDUCA- TION FOR INCLUSIVE EDUCATION IN PRACTICE
}

\begin{abstract}
This study aimed to examine the curricular aspects related to inclusive education treated in the discipline of adapted motor activity or similar in Physical Education training of the State of Santa Catarina. Participants were randomly selected $(n=17)$ in 12 Higher Education Institutions in Santa Catarina. Data were collected through semi-structured interview and questionnaire. The categorical data were analyzed using content analysis and numerical data using descriptive statistics. It can be concluded that participants realize that the curricular aspects have sought training for inclusive action, but through isolated teachers actions in poor physical, human and methodologics resources, thus generating weaknesses affecting university education for inclusive action. One can also conclude that the participants understand that the disciplines in the area of adapted prevalently present a theoretical-practical and technical-therapeutic character teaching and are taught by professors relatively new in university teaching, qualified in stricto sensu level and without students with disabilities.
\end{abstract}

Keywords: Faculty. Physical Education and Training. Education, Higher.

\section{ASPECTOS CURRICULARES ASOCIADOS A LA FORMACIÓN DE LA EN- SEÑANZA SUPERIOR DE LA EDUCACIÓN FÍSICA EN LA PARTICIPACIÓN DE LA EDUCACIÓN INCLUSIVA}

\section{Resumen}

Este estudio tiene como objetivo analizar los aspectos curriculares asociados a la formación de la enseñanza superior en la Educación física del Estado de Santa Catarina para la actuación en la educación inclusiva. Los sujetos fueron seleccionados aleatoriamente $(n=17)$ en 12 Instituciones Catarinenses de Enseñanza Superior. Los datos fueron colectados por medio de entrevista semi-estructurada y cuestionarios. Los datos de categorías fueron determinados por medio de análisis de contenido y los datos numéricos por medio de estadística descriptiva. Se puede concluir que los aspectos curriculares han buscado la formación para la actuación inclusiva, pero con acciones docentes aisladas y con carencia de recursos físicos, humanos y metodológicos que puede provocar perjuicios en el proceso de enseñanza. También se puede concluir que los participantes entienden que la disciplina en el área adaptada o diferencial presentan una enseñanza teórico-práctica y técnicaterapéutica, donde la docencia universitaria se realiza por profesores relativamente nuevos, calificados en el ámbito estricto y no teniendo alumnos con discapacidad.

Palabras-Claves: Docentes. Educación y Entrenamiento Físico. Educación Superior

Pensar a Prática, Goiânia, v. 17, n. 1, p. 01-294, jan./mar. 2014 


\section{Referências}

AGUIAR J. S.; DUARTE, E. Educação inclusiva: um estudo na área da Educação Física. Revista Brasileira de Educação Especial, Marília, v.11, n.2, p.223-240, maio/ago., 2005.

AMMAH, J. O. A.; HODGE, S. R. Secondary Physical Education Teachers' Beliefs and Practices in Teaching Students with Severe Disabilities: A Descriptive Analysis. High School Journal, v. 89, n. 2, p. 40-54, dez./jan., 2005-2006.

ALVES-MAZZOTTI, A. J.; GEWANDSZNAJDER, F. O método nas ciências naturais e sociais: pesquisa quantitativa e qualitativa. 2. Ed. São Paulo: Pioneira Thomson Learning, 2002.

BARBOSA, C. P.; CESARIO, A. C. F.; BENTO, N. D. Análise do preparo do professor de Educação Física em atuar com crianças do ensino fundamental vítimas de paralisia cerebral visando inclusão escolar. Revista Saúde e Pesquisa, Maringá, v. 2, n. 3, p.301-309, set./dez., 2009.

BARDIN, L. Análise de conteúdo. Lisboa: Edições 70, 2000.

BARROS, J. M. C. Educação Física na UNESP de Rio Claro: Bacharelado e Licenciatura. Motriz, Rio Claro, v. 1, n.1, p.71-80, jun., 1995.

BOGDAN, R.; BIKLEN, S. K. Investigação qualitativa em educação: uma introdução à teoria e aos métodos. Porto: Porto, 1994.

BRASIL. Ministério da Educação. Conselho Federal de Educação. Resolução n.3, 16 jan.,1987. Diário Oficial [da] República Federativa do Brasil, Poder Executivo, Brasília, DF, set. 1987.

. MEC. Presidente da República Federativa do Brasil. Constituição da República Federativa do Brasil. Diário Oficial [da] República Federativa do Brasil, Brasília, DF, 5 out. 1988.

. Ministério da Educação. Lei 9.394/96, de 20 de dezembro de 1996. Estabelece as diretrizes e bases da educação nacional. Diário Oficial [da] República Federativa do Brasil, Poder Executivo, Brasília, DF, 23 dez. 1996. Seção 1, p. 27833. 
. Ministério da Educação. Conselho Nacional de Educação. Resolução CEB, n. 1. Diário Oficial [da] República Federativa do Brasil, Brasília, DF, 19 jul. 2000. Seção 1, p. 18.

. Ministério da Educação. Resolução CNE/CP 1/2002, de 18 de fevereiro de 2002. Institui a duração e a carga horária dos cursos de Licenciatura, de graduação plena. Diário Oficial [da] República Federativa do Brasil, Brasília, DF, 4 mar. 2002. Seção 1, p. 8.

Ministério da Educação. Lei n ${ }^{0} 11.096$, de 13 de janeiro de 2005. Institui o Programa Universidade para Todos - PROUNI, regula a atuação de entidades beneficentes de assistência social no ensino superior; altera a Lei $\mathrm{n}^{\mathrm{O}} 10.891$, de 9 de julho de 2004, e dá outras providências. Diário Oficial [da] República Federativa do Brasil, Brasília, DF, 14 jan. 2005. Seção 1, p. 7.

. Ministério da Educação. Decreto $n^{0}$ 5.773, de 9 de maio de 2006. Dispõe sobre o exercício das funções de regulação, supervisão e avaliação de instituições de educação superior e cursos superiores de graduação e seqüenciais no sistema federal de ensino. Diário Oficial [da] República Federativa do Brasil, Brasília, DF, 10 maio 2006. Seção 1, p. 6.

. Ministério da Educação. Plano de Desenvolvimento da Educação: razões, princípios e programas. Brasília, DF: [s. n.], 2007.

Ministério da Educação. Súmula: Política nacional de educação especial na perspectiva da educação inclusiva. Caderno Cedes, Campinas, v. 28, n. 75, p.269-273, maio/ago., 2008.

CRUZ, G. C.; FERREIRA, J. R. Processo de formação continuada de professores de Educação Física em contexto educacional inclusivo. Revista Brasileira de Educação Física Especial, São Paulo, v.19, n. 2, p.163-180, abr./jun., 2005.

DUARTE, E. A. Formação do Profissional em Atividade Motora Adaptada In: MENDES, E.G.; ALMEIDA, M. A.; ALBUQUERQUE L. C (Orgs.). Temas em Educação Especial: avanços recentes. São Carlos: EdUFSCAR, 2004.

FALKENBACH, A. P. Inclusão: perspectivas para as áreas da Educação Física, saúde e educação. São Paulo: Jundiaí, 2010.

FALKENBACH, A. P. et al. A questão da integração e da inclusão nas aulas de Educação Física. Lecturas: Educacion Fisica y Deportes, Buenos Aires, v. 11, n. 106, mar., 2007a. Não paginado. Disponível em< 
http://www.efdeportes.com/efd106/a-questao-da-integracao-e-da-inclusao-nasaulas-de-educacao-fisica.htm>. Acessado em 10 de nov. 2010.

FALKENBACH A. P. et al. A inclusão de crianças com necessidades especiais nas aulas de Educação Física na educação infantil. Movimento, Porto Alegre, v. 13, n. 2, p.37-53, maio/ago., 2007b.

FILUS, J.; MARTINS Jr., J. Reflexões sobre a formação em Educação Física e a sua aplicação no trabalho junto às pessoas com deficiência. Revista da Educação Física/UEM, Maringá, v.15, n.2, p. 79-87, jul./dez., 2004.

GHIRALDELLI Jr., P. Educação Física progressista: a pedagogia crítico-social dos conteúdos e a Educação Física brasileira. São Paulo: Loyola, 2001.

GOLDER, G.; NORWICH, B.; BAYLISS, P. Preparing teachers to teach pupils with special educational needs in more inclusive schools: evaluating a PGCE development. British Journal of Special Education, v. 32, n.2, p. 92-99, jun., 2005.

GOMES, N. M. Análise da disciplina e Educação Física especial nas Instituições de Ensino Superior públicas do Estado do Paraná. 2007. f. Tese (Doutorado)-Faculdade de Educação Física, Universidade Estadual de Campinas, Campinas, 2007.

GORGATTI, M. G.; DA COSTA, R. F. Atividade Física Adaptada: qualidade de vida para pessoas com necessidades especiais. 2 ed. rev. e ampl. Barueri, SP: Manole, 2008.

GORGATTI, M.G.; DE ROSE Jr., D. Percepções dos Professores Quanto à Inclusão de Alunos com Deficiência em Aulas de Educação Física. Movimento, Porto Alegre, v.15, n.2, p.119-140, abr.jun., 2009.

GORGATTI, M. G., et al. Atitudes dos professores de Educação Física do ensi no regular com relação a alunos portadores de deficiência. Revista Brasileira de Ciência e Movimento, Brasília, v.12, n.2, p.63-68, jun., 2004.

ILHA, F. R. S. O curso de licenciatura em Educação Física e os desafios da formação profissional: o processo de ensinar e aprender a docência. 2010. Dissertação (Mestrado)-Centro de Educação, Universidade Federal de Santa Maria, Santa Maria, 2010. 
LAVILLE, C.; DIONNE, J. A construção do saber: manual de metodologia da pesquisa em ciências humanas. Porto Alegre: Artes Médicas; Belo Horizonte: EUFMG, 1999.

MAUERBERGUE DE CASTRO, E. M. de. Atividade Física Adaptada. Ribeirão Preto, SP: Tecmedd, 2005.

MONTEIRO, V. M. T. Q. Atitudes dos professores de Educação Física no ensino de alunos com deficiência. Tradução, validação e análise para a Cultura Portuguesa do Instrumento PEATID-III. 2008. Dissertação (Mestrado)-Faculdade de Desporto, Universidade do Porto, Porto, 2008.

MOREIRA, A. F. B.; Silva, T. T. Currículo, cultura e sociedade. São Paulo: Cortez, 1995.

NEGRINE, A. Instrumentos de coleta de informações na pesquisa qualitativa. In: TRIVIÑOS, A. N. S.; MOLINA NETO, V. (Orgs.). A pesquisa qualitativa na Educação Física: Alternativas metodológicas. Porto Alegre: UFRGS/SULINA, 1999. p. 61-94.

NUNES SOBRINHO, F. P.; NAUJORKS, M. I. (Orgs.). Pesquisa em Educação Especial: o desafio da qualificação. Bauru: Edusc, 2001.

OLIVEIRA, F. I. W. O professor diante da inclusão do aluno com visão subnormal: a utilização de materiais didáticos adaptados para o ensino. $163 \mathrm{f}$. Tese (Doutorado em Educação)-Faculdade de Filosofia e Ciências, Universidade Estadual Paulista, Marília, 2001.

PALLA, A.C.; CASTRO, E.M. Atitude de professores e estudantes de Educação Física em relação ao ensino de alunos com deficiência em ambientes inclusivos. Revista da Sobama, v. 9, n. 1, p. 25-34, 2004.

PEDRINELLI, V. J. Possibilidades na diferença: o processo de "inclusão" de todos nós. Integração, v. 4, p. 31-34, 2002.

PEDRINELLI, V. J.; VERENGUER, R. DE C. G. Educação Física: introdução ao universo das possibilidades. In: GORGATTI, M. G.; COSTA, R. F. Atividade Física Adaptada: qualidade de vida para pessoas com necessidades especiais. Barueri: Manole, 2005. 
PEREIRA, F. O Observatório dos Apoios Educativos. In: CONSELHO NACIONAL DE EDUCAÇÃO (Ed.), Uma educação inclusiva a partir da escola que temos. Lisboa: Ministério da Educação, 1999.

REID, G. Preparação Profissional em Atividade Física Adaptada: perspectivas norte americanas. Revista da Sobama, Rio Claro, v. 5, n. 1, p. 1-4, 2000.

RODRIGUES, D. A. Educação Física perante a educação inclusiva: reflexões conceptuais e metodológicas. Revista da Educação Física/UEM, Maringá, v. 14, n. 1, p. 67-73, jan./jun., 2003.

. A Inclusão na Universidade: limites e possibilidades da construção de uma Universidade Inclusiva. Revista Educação Especial, Santa Maria, v. 23, n. 2, p. 9-16, 2004.

Atividade Motora Adaptada: a alegria do corpo. São Paulo: Artes Médicas, 2006.

RIZZO, T. L.; KIRKENDALL, D. R. Teaching Students With Mild Disabilities: What Affects Attitudes of Future Physical Educators? Adapted Physical Activity Quarterly, v. 12, p. 205-216, 1995.

TOLOCKA, R. E. Educação Física e diversidade humana. In: DE MARCO, A. Educação Física: cultura e sociedade. Campinas: Papirus, 2008.

SATO, T. et al. Japanese physical education teachers' beliefs about teaching students with disabilities. Sport Education and Society, v. 12, n. 2, p. 211-230, 2007.

SANTOS, M. P. Inclusão/Exclusão na Formação Inicial de Docentes de Universidades Públicas: Brasil, Cabo Verde, Córdoba e Sevilha - Relatório Final de Pesquisa, Rio de Janeiro, 2010.

SILVA, S. B. Análise das relações existentes na legislação que orienta a formação profissional dos especialistas em Educação Física e Desportos e os planos nas áreas educacional e desportiva no Brasil. 1993. f. Dissertação (Mestrado) Escola de Educação Física, Universidade de São Paulo, São Paulo,1993.

SILVA, L. R. S.; REIS, M. B. F. Educação Inclusiva: o desafio da formação de professores. Revista de Educação, Linguagem e Literatura, Inhumas, v. 3, n. 1, p. 7-17, 2011. 
SILVA, R. Características do estilo de vida e da qualidade de vida de professores do ensino superior público em Educação Física. 264 f. Tese (Doutorado)Programa de Pós-Graduação em Engenharia de Produção, Centro Tecnológico, Universidade Federal de Santa Catarina, Florianópolis, 2006.

SILVA, R.; SILVEIRA Jr., R. Aspectos legais e metodológicos associados à inserção educacional de alunos com deficiência na Educação Física do ensino privado. Lecturas: Educacion Fisica y Deportes, v. 13, n. 129, 2009. Disponível em: $<$ http://www.efdeportes.com/efd129/insercao-educacional-de-alunos-comdeficiencia-na-educacao-fisica.htm> Acesso em 10 de Nov. 2010.

SILVA FILHO, J. L. F.; SILVA, M. C. R. F. O movimento de inclusão na universidade: relações entre ergonomia e educação, 2008. Disponível em

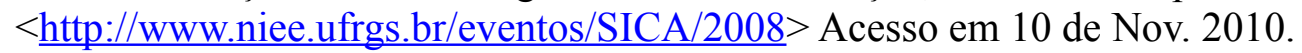

SKARBREVIK, K. J. The Quality of Special Education for Students with Special Needs in Ordinary Classes. European Journal of Special Needs Education, v. 20, n. 4, p. 387-401, 2005.

Recebido em: 07/08/2012

Revisado em: 27/01/2013

Aprovado em: 06/05/2013

Endereço para correspondência:

paulogutierresfilho@ig.com.br

Paulo José Barbosa Gutierres Filho

Universidade do Estado de Santa Catarina - UDESC

Av. Madre Benvenuta, 2007

Itacorubi - Florianópolis - SC

CEP: 88.035-001 